\title{
Application of Analytic Hierarchy Process (AHP) and Simple Additive Weighting (SAW) Methods in Mapping Flood-Prone Areas
}

\author{
$\mathrm{Yu}$ CHEN a,b,1 \\ ${ }^{a}$ State Key Laboratory of Hydraulics and Mountain River Engineering, Sichuan \\ University, Chengdu 610065, China \\ ${ }^{b}$ Institute for Risk and Disaster Reduction, University College London, Gower Street, \\ London WC1E 6BT, United Kingdom
}

\begin{abstract}
The first step of formulating flood risk management strategies is to identify the flood at-hazard areas. This study aims to map flood-prone areas with different hazard levels in the Dadu River basin, using simple additive weighting (SAW) and analytic hierarchy process (AHP) methods and the geographic information systems (GIS) tool. The grid map of selected criteria, rainfall, topography, drainage, and the usage of land were processed and applied to estimate the flood hazard index (FHI) values in the basin in the GIS environment. The resultant map illustrates the spatial distribution of basin-scale flood at-hazard areas, can be used as powerful guidance of implementing preventing and alleviating flood risk for decision-makers and managers, and extended application in other basins or disaster fields.
\end{abstract}

Keywords. Flood hazard, flood-prone areas, SAW, AHP, GIS

\section{Introduction}

The flood is a multi-attribute natural hazard and often causes catastrophic damages and enormous impacts to the human, society, economy and environment, and has become a worldwide problem. The increasing flood occurrence necessitates the development of flood management, where flood hazard evaluation is one important part with the research purpose of obtaining the spatial distribution of flood-prone areas, which is a basis of implementing effective management decision-making.

Numerous hazard assessment methods have been developed, which include statistical analysis, uncertainty analysis, and multi-criteria evaluation (MCE), etc. [1]. In recent years, more and more researchers pay attention to the $\mathrm{MCE}$, especially the geographic information system (GIS)-based MCE method, which is a useful tool for

\footnotetext{
${ }^{1}$ Corresponding Author: Yu Chen, State Key Laboratory of Hydraulics and Mountain River Engineering, Sichuan University, Chengdu 610065, China; E-mail: rainchen393@hotmail.com

This work was supported by Sichuan Science and Technology Program [grant number 2019YFH0140]; International Visiting Program for Excellent Young Scholars of SCU; and the National Natural Science Foundation of China [grant numbers 41501554].
} 
processing spatial data and can incorporate all relevant types of consequences [2]. Jonkman et al. (2008) [3], Meyer et al. (2009) [4], Wang et al. (2011) [5], Papaioannou et al. (2015) [6] successively researched its application in flood risk assessment.

Analytic hierarchy process (AHP) with the major advantage of simple GIS integration is the most commonly used MCE method in the flood risk management field [7]. SAW is also a broadly applied MCE approach, and its combination with GIS can carry out the spatial analysis of the evaluation and decision situations [8]. The researches of [9-11] have successively identified the practicability of the integration of AHP, SAW and GIS. Therefore, this study applies SAW and AHP methods to establish a GIS-based MCE model for mapping flood hazard areas with different classes to support flood risk management decision-making.

\section{Methodology}

\subsection{Study Area}

Dadu River basin is located in Sichuan Province, Southwestern China (Figure 1), covers an area of $77400 \mathrm{~km}^{2}$, and has been heavily hydropower-developed in the form of cascade reservoirs. The basin has a complex climate and geological environment, and is a global climate change sensitive area and the main geological activity area.

The basin is prone to flooding due to heavy precipitation. Since 1956, several historical flood surveys have been carried out in the basin. The surveyed historical flood years are 1786, 1892, 1904, 1939, and 1955. Except for the mountain collapse-induced flood in 1786, the biggest flood in the investigation is the 1904 flood, followed by the 1939 flood. For the 1904 historic flood event, caused by rare and long-term rainfall in the upstream of the basin, the flood return periods in the upper reaches, the middle reaches and the lower reaches are more than 200-year, 100-year, and more than severaldecade, respectively. The heavy flood in 1939 was mainly formed by the rainstorm in the middle and lower reaches.

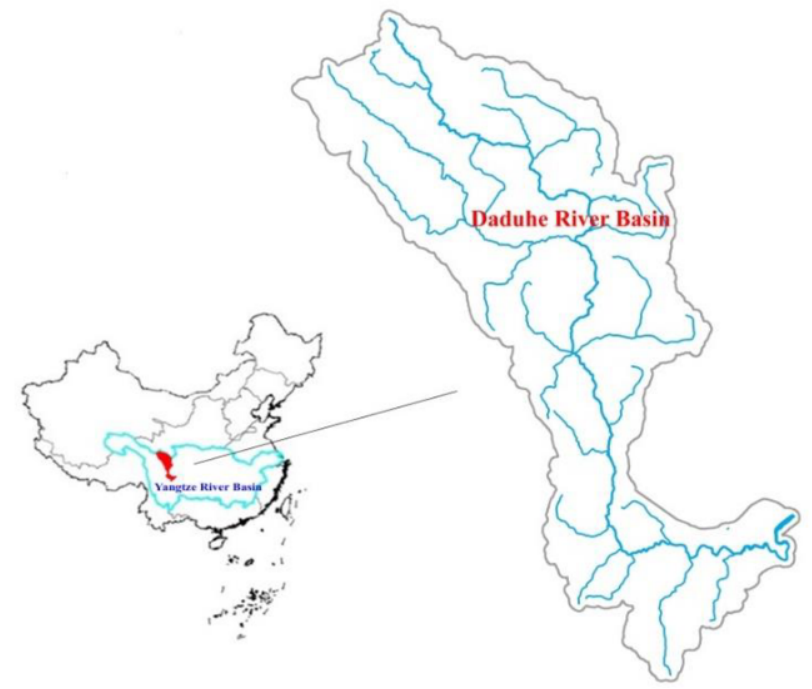

Figure 1. Location of the Dadu River basin. 


\subsection{Criteria Identification}

The criteria selection is a vital step for flood hazard evaluation. In the study, five indicators, maximum five-day precipitation (M5DP, $C_{1}$ ), digital elevation model (DEM, $C_{2}$ ), slope $\left(C_{3}\right)$, land cover use ( $\left.\mathrm{LCU}, C_{4}\right)$, and distance to the river (DTR, $C_{5}$ ), are selected based on the previous studies [12-16] and the actual situation of the study area.

M5DP is a representative rainfall intensity indicator and abstracted from the meteorological-station data (http://cdc.cma.gov.cn/) in the basin. DEM is the most important criterion for flood hazard assessment, can be extracted from the $30 \times 30 \mathrm{~m}$ ASTER GDEM data (http://www.gscloud.cn/), and so does slope. The slope is crucial to regulate the flow of surface water, and partially controls the infiltration process. The regions with lower slope are prone to flood hazard, while higher slope provides an easy passage to pass away the flood. Areas closed to rivers are much more likely to suffer more frequent floods. To quantify this indicator, sequential buffers were hence created along the rivers and corresponding values were assigned, for instance, the rivers are set to 0 , and similarly, the regions far more away from rivers are assigned larger values.

The river system is extracted based on ASTER GDEM data. LULC illustrates the land cover, reflects varying degrees of flood interception, and can be downloaded from http://www.gscloud.cn/.

To quantify these criteria and delineate different flood hazard zones in the basin, indicator data sets garnered from various sources should be input into GIS and converted to spatial criteria map layers with the same spatial resolution (30m grid cell size).

\subsection{AHP and SWA Methods}

AHP as the most common used MCE method is utilized to calculate criteria weights. Based on a preference matrix, all evaluated criteria are compared against each other in pairs, and assigned weights correspondingly. Then the assessment results can be derived by aggregating the criteria with determined weights in selected combination methods [2].

The pairwise comparison matrix $A=\left[a_{i j}\right],(i=1,2, \ldots, m, j=1,2, \ldots, n)$ is defined as follows:

$$
A=\left[\begin{array}{cccc}
1 & a_{12} & \cdots & a_{1 n} \\
1 / a_{12} & 1 & \cdots & a_{2 n} \\
\vdots & \vdots & \vdots & \vdots \\
1 / a_{1 n} & 1 / a_{2 n} & \cdots & 1
\end{array}\right]
$$

Where the entry $a_{i j}$ expresses how much the criteria $x_{i}$ is preferred to criteria $x_{j}$, if $a_{i j}=a$, then $a_{j i}=1 / a, a>0$. If all criteria are already known, $a_{i j}$ equals to the ration of relative weights of criteria $x_{i}$ and $x_{j}, w_{i} / w_{j}$. To determine the relative weights, the pairwise judgement is made by decision makers, which is based on the rule of Saaty (1977) [17] with a 9-point scale from 1 to 9 in Table 1 . The consistency ratio (CR) calculated in terms of Eq. (2) is used to check the consistency of judgement. If CR is less than 0.1 , then the judgement can be accepted.

$$
C R=C I / R I
$$


$\mathrm{CI}$ is consistency index and denoted as:

$$
C I=\left(\lambda_{\max }-n\right) /(n-1)
$$

where $\lambda_{\max }$ is the largest eigenvalue derived from the paired comparison matrix, $n$ is the number of criteria.

In Eq. (2), RI is random index, and obtained according to Table 2 defined by Saaty (1977) [17].

Table 1. Scales for pairwise comparisons.

\begin{tabular}{ll}
\hline Intensity of importance & Definition \\
\hline 1 & Equal importance \\
2 & Weak \\
3 & Moderate importance \\
4 & Moderate plus \\
5 & Strong importance \\
6 & Strong plus \\
7 & Demonstrated importance \\
8 & Very importance \\
9 & Extreme importance \\
\hline
\end{tabular}

Table 2. Random index (RI).

\begin{tabular}{llllllllll}
\hline $\boldsymbol{n}$ & 1 & 2 & 3 & 4 & 5 & 6 & 7 & 8 & 9 \\
\hline $\boldsymbol{R I}$ & 0 & 0 & 0.58 & 0.9 & 1.12 & 1.24 & 1.32 & 1.41 & 1.45 \\
\hline
\end{tabular}

SAW is based on the weighted summation concept to estimate the flood hazard index (FHI) value, which is specified in terms of the following formulas.

$$
\begin{gathered}
F H I=\sum_{j=1}^{n} w_{j} r_{i j} \\
r_{i j}=\frac{x_{i j}-\min x_{i j}}{\max x_{i j}-\min x_{i j}}
\end{gathered}
$$

where $x_{i j}$ is the value of $i$ th alternative on $j$ th criteria, $r_{i j}$ is the normalized value of $i$ th alternative on $j$ th criteria, $\max x_{i j}$ and $\min x_{i j}$ are the maximum and minimum values of $x_{i j}$, respectively, $w_{j}$ is $j$ th criteria weight calculated by AHP method, and $n$ is the criteria number.

\section{Results and Discussion}

Constructing a pairwise matrix is the necessary step of using the AHP method. Then, criteria weights and the CR can be calculated (Table 3). The resultant CR is less than 0.1 , which indicates the comparison is consistent and the assigned weights are appropriate. It can be seen that DEM is assigned the highest weight, followed by slope, DTR, and M5DP. LUC is identified as less important. This matches the fact that the flood is mainly driven by rainfall, and the driving force will increase with the facilitation of topography to runoff and the de-vegetation of landscapes. 
After using the SWA method to calculate FHI values based on the weighted criteria layers, the derived flood hazard map was reclassified into five levels of lowest, low, moderate, high, and highest (Figure 2) by using the natural breaking method, and the corresponding areas of each level account for $6 \%, 24 \%, 38 \%, 24 \%$, and $8 \%$ of the basin, respectively.

The results demonstrated that the east part of the downstream presents low to lowest flood hazard potentiality as the elevation and slope is very high comparing with other regions. About $38 \%$ of the basin area is distributed in the moderate flood hazard zone, which is the overriding hazard level and spread over a wide range, without a uniform distribution pattern. The highest flood potential area is mainly distributed in the midstream of the basin where a rainfall center is located, and elevation and slope are lower, which plays a crucial role to control the flood potentiality of an area. The area zoned as the highest flood hazard level needs great attention of risk administrative organization to prevent more serious flood hazard situations in the future.

Table 3. Pairwise comparison matrix, consistency ration and weights of the criteria.

\begin{tabular}{lllllll}
\hline & LUC & M5DP & DTR & slope & DEM & Eigen values \\
\hline LUC & 1 & & & & 0.0548 \\
M5DP & 4 & 1 & & & 0.1206 \\
DTR & 4 & 2 & 1 & & 0.1580 \\
slope & 4 & 3 & 3 & 1 & & 0.2884 \\
DEM & 4 & 3 & 3 & 2 & 1 & 0.3782 \\
\hline
\end{tabular}

Consistency ration: 0.07

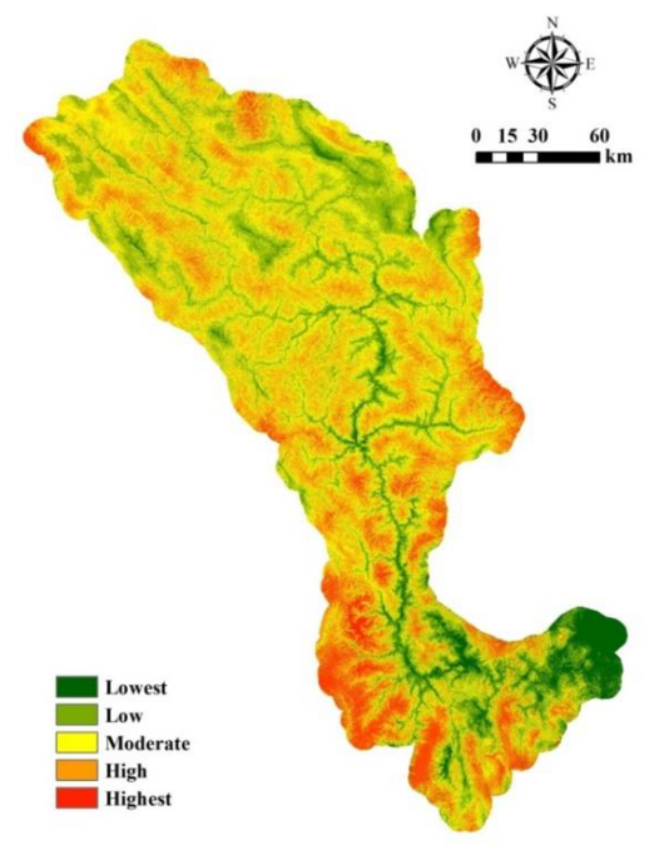

Figure 2. Flood hazard level map in the Dadu River basin. 
Assessing the basin-scale flood hazard is an effective way for accumulating correlated disaster risk information to support risk management decision-making of preventing and alleviating the flood disaster. To identify the flood hazard-prone areas, risk researchers and decision-makers have developed several approaches to predict the spatial distribution of flood hazard levels, wherein how to discern and utilize the most optimal method to generate the flood hazard map for specific areas is the common difficulty. In this context, this study originatively combined AHP and SAW to build a GIS-based MCE framework for mapping the basin-scale flood hazard. As the most famous and popular multi-criteria decision evaluation methods, AHP is usable for simplifying the assessment of complicated, unorganized and multi-attribute problems, driving criteria weights by using subjective judgments and empirical data, and allowing the calculation of the consistency for the evaluation procedure [18]. SAW is a proportional linear transformation of the raw data, which keeps the relative order of magnitude of the standardized scores equal. The SAW-based flood hazard index is calculated by summing up all alternative scores which can be derived by multiplying the normalized criteria weights by the standardized rating value of each corresponding criterion [19]. It is worth noting that the total weight must be 1 during the weighting, which makes it is a difficulty that assigning the right weight in terms of criterion priorities. While the AHP, assigning and validating weights by comparing the importance degree of each criterion and calculating the consistency ratio, can meet the requirement. Therefore, the combination of AHP and SAW is reasonable. The results of the case study indicate the availability of the combination of AHP and SAW in the Dadu River basin.

\section{Conclusions}

The estimation and mapping of the spatial flood hazard distribution in a GIS environment are essential for impactful flood risk management. In the study, the flood hazard in the Dadu River basin is identified based on an AHP-SAW method and the GIS tool. Specifically, the information of hydrometeorology, topography, drainage, and land usage aspects are weighted by the AHP method and integrated by the SAW method. The flood-prone areas in the basin are divided into five levels from lowest to highest based on the calculated FHI values. The results are fundamental for formulating effective flood risk management planning and measures. The combined method of AHP and SAW can be easily extended to other river basins if the required indicator data can be collected, and other disaster fields, such as landslide, erosion and fire. Present researches in the field mostly used static variables, and future studies can explore how to mix dynamic variables, such as climate and land use change data, with static variables to map the flood hazard, which can be used as scientific support of real-time flood risk decisionmaking.

\section{References}

[1] Jiang WG, Deng L, Chen LY, Wu JJ and Li J. Risk assessment and validation of flood disaster based on fuzzy mathematics. Progress in Natural Science. 2009; 19:1419-1425.

[2] Chen Y, Liu R, Barrett D, Lei G, Zhou MW, Renzullo L and Emelyanova I. A spatial assessment framework for evaluating flood risk under extreme climates. Science of the Total Environment. 2015; 
538: 512-523.

[3] Jonkman SN, Kok N and Vrijling JK. Flood risk assessment in the Netherlands: a case study for dike ring South Holland. Risk Analysis. 2008; 28:1357-1374.

[4] Meyer V, Scheuer S and Haase D. A multi-criteria approach for flood risk mapping exemplified at the Mulde river, Germany. Natural Hazards. 2009; 48:17-39.

[5] Wang Y, Li Z and Tang Z. A GIS-based spatial multi-criteria approach for flood risk assessment in the Dongting Lake Region, Hunan, Central China. Water Resources Management. 2015; 25: 3465-3484.

[6] Papaioannou G, Vasiliades L and Loukas A. Multi-criteria analysis framework for potential flood prone areas mapping. Water Resources Management. 2015; 29:399-418.

[7] de Brito MM, Evers M. Multi-criteria decision-making for flood risk management: a survey of the current state of the art. Natural Hazards and Earth System Sciences.2016; 16:1019-1033.

[8] Malczewski J and Rinner C. Multicriteria decision analysis in geographic information science. Springer Berlin, 2015.

[9] Çağıl K, Vedat D, Can A and Mehmet LS. Preparation of a geotechnical microzonation model using Geographical Information Systems based on Multicriteria Decision Analysis. Engineering Geology. 2006; $87: 241-255$.

[10] Kandilioti G and Makropoulos C. Preliminary flood risk assessment: the case of Athens. Natural Hazards. 2012; 61: 441-468.

[11] Dewan A. Floods in a megacity: geospatial techniques in assessing hazards, risk and vulnerability. Springer, Dordrecht, 2013.

[12] Fernández DS and Lutz MA. Urban flood hazard zoning in Tucumán Province, Argentina, using GIS and multicriteria decision analysis. Engineering Geology. 2010; 111: 90-98.

[13] Nerantzis K, Ioannis K and Thomas P. Assessment of flood hazard areas at a regional scale using an index-based approach and Analytical Hierarchy Process: Application in Rhodope-Evros region, Greece. Science of the Total Environment. 2015; 538:555-563.

[14] Kourgialas NN and Karatzas GP. A national scale flood hazard mapping methodology: The case of Greece - Protection and adaptation policy approaches. Science of the Total Environment. 2017; 601-602: 441-452.

[15] Hu SS, Cheng XJ, Zhou DM and Zhang H. GIS-based flood risk assessment in suburban areas: a case study of the Fangshan District, Beijing. Natural Hazards. 2017; 87: 1525-1543.

[16] Ahmed EMA, Ayman MN and Omar EMA. Evaluation of flood susceptibility mapping using logistic regression and GIS conditioning factors. Arabian Journal of Geosciences. 2018; 11:765.

[17] Saaty TL. A scaling method for priorities in hierarchical structures. Journal of Mathematical Psychology. 1977; 15: 234-281.

[18] Sedghiyan D, Ashouri A, Maftouni N, Xiong QG, Rezaee E and Sadeghi S. Prioritization of renewable energy resources in five climate zones in Iran using AHP, hybrid AHP-TOPSIS and AHP-SAW methods. Sustainable Energy Technologies and Assessments. 2011; 44:101045.

[19] Chabuk AJ, Al-Ansari N, Hussain HM, Sven S and Roland P. GIS-based assessment of combined AHP and SAW methods for selecting suitable sites for landfill in Al-Musayiab Qadhaa, Babylon, Iraq. Environmental Earth Sciences. 2017; 76:209. 